\title{
TITLE:
}

\section{$<$ Note> Snare Injuries of Chimpanzees in the Kalinzu Forest, Uganda.}

AUTHOR(S):

Hashimoto, Chie

CITATION:

Hashimoto, Chie. <Note> Snare Injuries of Chimpanzees in the Kalinzu Forest, Uganda.. Pan Africa News 1999, 6(2): 20-22

ISSUE DATE:

1999-12

URL:

http://hdl.handle.net/2433/143377

RIGHT:

Copyright (C) Pan Africa News. 


\section{<NOTE>}

\section{Snare Injuries of Chimpanzees in the Kalinzu Forest, Uganda.}

Chie Hashimoto

(Primate Research Institute, Kyoto University)

\section{Introduction}

In recent years, a great concern has been raised about injuries to the chimpanzees caused by encounters with snares and traps. It has been reported that one-third of group members suffered injuries caused by encounters with snares in the Budongo Forest, Uganda (1). A recent workshop on Population and Habitat Viability Assessment of Uganda's Chimpanzees held in Entebbe in 1997 has drawn attention to the need for more study on snare-induced injuries in wild chimpanzees (2). This paper reports the frequency of injuries to the chimpanzees in the Kalinzu Forest and a possible cause of those injuries.

\section{Methods}

The Kalinzu Forest Reserve, which is located in southwestern Uganda $\left(0^{\circ} 17^{\prime} \mathrm{S}, 30^{\circ} 07^{\prime} \mathrm{E}\right)$ is classified as a medium altitude moist evergreen forest. Six species of diurnal primates, including 
chimpanzees, inhabit this area $(3,4)$. There is a sawmill in the western part of the Kalinzu Forest, where about 100 people live, including the workers and their families. The Kalinzu Forest is surrounded by villages and fields. Local people do not hunt primates, but they do hunt duikers and bushpigs with snares.

This study was carried out in three periods: 1) from October 1992 to March 1993, 2) from June 1997 to March 1998, 3) from July 1998 to October 1998. Since 1997, I have habituated one group of chimpanzees that ranges around the sawmill (4). Most of the adult male members (16 individuals) were identified, while only a few adult females and immature individuals were identified.

I observed injuries in limbs by monitoring the chimpanzees with binoculars. I used the criteria of Walker (5) to judge whether the observed injury was caused by an encounter with snares.

\section{Results}

Ten of the 16 identified adult male chimpanzees had injuries to their limbs, and nine of them (56.2\%) had injuries considered to be caused by an encounter with snares. These injuries were divided into three categories according to the probability that the injury was caused by an encounter with snares.

Injuries of two males were apparently due to an encounter with snares because they had wire embedded in their hands. One of them had wire in his left hand when identified and he did not use the hand. The other male had wire in the right hand, and the fingers of the hand, except for the middle finger, appeared to function normally. After the wire was removed, he used the right hand normally except that the middle finger remained stiff.

The complete loss of a hand / foot (two males), a clawed hand (one male), and a paralysed hand with hair loss (one female) were considered to have a high probability of being caused by encounters with snares (5).

I observed three males with fingers cut near the root, one male with hair loss near the ankle, and one female with paralysed fingers.
Such injuries may have been caused by encounters with snares or by infection with leprosy (5). As there are frequent visits by people in the Kalinzu Forest, there is the possibility of cross-species transmission of leprosy. However, chimpanzees with these injuries did not show any other abnormality that would have resulted from leprosy. Therefore, these kinds of injuries were more probably caused by encounters with snares than by infection with leprosy.

\section{Discussion}

There was a comparatively high proportion of chimpanzee injuries caused by encounters with snares. This tendency was also observed at two chimpanzee research sites in Uganda. In the Budongo Forest, seven of 27 adult chimpanzees and four of six young chimpanzees had limb disabilities (1). In the Kibale Forest, $10-13$ of about 100 chimpanzees were observed to have limb injuries (6). There is little hunting of primates in Uganda, and the snares/traps that injured chimpanzees are set for duikers, bushpigs, etc. These snares rarely kill chimpanzees but do cause serious injuries. Stokes and Byrne (7) reported that most of the chimpanzees with injuries did not show a decline in feeding efficiency. However, snare injuries may cause infection with diseases and as a result affect survival and reproduction. More studies are needed to investigate the actual situation of snare injuries and their long-term effects.

\section{Acknowledgement}

We are grateful to Uganda National Council for Science and Technology, Uganda Forestry Department, and Uganda Wildlife Authority for permission to work in the Kalinzu Forest. We are also grateful to Mr. M.G. Moses and staff of the Nkombe Forest Station for their support. We thank the Nkombe Saw Mill for permission to stay at their guesthouse. We also thank Ugandan assistants for their help in the field. Dr. V. Reynolds, Dr. E.J. Stokes, and Mr. J.C. Walker kindly gave me valuable information on chimpanzee injuries in the Budongo Forest. 
This study was supported by grants under the Monbusho International Scientific Research Program awarded to Prof. T. Kano (No. 09041160).

\section{References}

(1) Reynolds. V.. Burch, D., Knight, J., Smith, R. \& Walter. J., 1996. The nature, causes and consequences of injuries sustained by wild chimpanzees in the Budongo Forest, Uganda. Abstract, XVIth Congress of the International Primatological Society.

(2) IUCN Conservation Breeding Specialist Group, 1997. Forest conservation in relation to chimpanzees. In: Edroma, E.J., Rose N., Miller P.S. (eds.), Conserving the chimpanzees of Uganda: population and habitat viability assessment for Pan troglodytes schweinfurthii. IUCN Conservation Breeding Specialist Group, Apple Valley.

(3) Howard, P.C., 1991. Nature conservation in Uganda's tropical forest reserves. IUCN, Gland and Cambridge.

(4) Hashimoto, C., 1998 . Chimpanzees in the Kalinzu Forest, Uganda. Pan Africa News 5: 6-8.

(5) Walker, J.C., 1995. The etiologies of major limb abnormalities amongst chimpanzees in the Sonso area of the Budongo Forest. Master thesis of Oxford University.

(6) Ghiglieri, M.P., 1984. The chimpanzees of Kibale Forest, Columbia University Press, New York.

(7) Stokes, E.J. \& Byrne, R.W., 1999. Feeding skills and the effect of injury on chimpanzees of the Budongo Forest, Uganda. 22nd Meeting of the American Society of Primatologists, New Orleans, Louisiana. 